\title{
A Filosofia da Educação como hermenêutica da contemporaneidade
}

Antonio Joaquim Severino

Professor da Universidade Nove de Julho

\section{Resumo}

O ensaio apresenta as grandes linhas do pensamento filosófico-educacional do Pedro Goergen, defendendo a posição de que ele pratica a Filosofia, em geral, e a Filosofia da Educação, em particular, como uma hermenêutica sustentada por reflexão rigorosa e crítica sobre a dimensão sociocultural, na perspectiva longitudinal do tempo histórico, abordando os contrapontos, as rupturas e continuidades, particularmente entre a modernidade e a pós-modernidade. Procede a um diagnóstico da profunda crise, de natureza ética e política, da civilização atual, sempre seguido da enunciação da necessidade e da possibilidade de superação da mesma, tarefa que vê como necessário compromisso da Filosofia.

Palavras-chave: Filosofia da Educação; Hermenêutica; Pedro Goergen.

\section{Abstract}

The paper presents the main lines of philosophical and educational thought of Peter Goergen, defending the position that he practices philosophy in general, and the Philosophy of Education, in particular, as a sustained hermeneutics by rigorous and critical reflection on the socio-cultural dimension in the longitudinal perspective of historical time, addressing the counterpoints, ruptures and continuities, particularly between modernity and postmodernity. Proceeds to a diagnosis of deep crisis, ethical and political, of the current civilization, always followed by the enunciation of the need and the possibility of overcoming it, task presented as necessary compromise by philosophy.

Keywords: Philosophy of Education; Hermeneutics; Peter Goergen.

\begin{tabular}{c}
\hline Filosofia e Educação [RFE] - Volume 8, Número 2 - Campinas, SP \\
Junho-Setembro de 2016 - ISSN 1984-9605 - p. 7-26
\end{tabular}




\section{Introdução}

evisitar a obra de Pedro Goergen é, sem dúvida, uma experiência
enriquecedora e muito gratificante, pela contribuição
significativa que ela traz para a compreensão das intrincadas malhas da cultura contemporânea e, consequentemente, das tarefas que cabem à educação, nesse complexo e contraditório cenário, ao praticar assim uma consistente proposta de Filosofia da Educação.

Este breve ensaio tem a ambição de apresentar, ainda que de uma forma muito sintética, as grandes linhas do pensamento filosóficoeducacional desse autor e, com isso, participar desta mais que merecida homenagem que ora lhe é rendida mediante a publicação deste dossiê. Iniciativa que visa traduzir o reconhecimento público pela contribuição de Pedro Goergen ao debate dos grandes problemas da educação contemporânea bem como à consolidação do campo epistêmico da Filosofia da Educação, em nosso contexto.

Sem nenhuma dúvida, Pedro Goergen revela-se como uma das mais importantes expressões do campo da Filosofia da Educação, em nosso universo acadêmico e cultural do momento, levando-se em conta a sistematicidade de sua produção, a profundidade de suas análises e reflexões, a agudez de sua percepção dos problemas educacionais, a capacidade de tornar acessíveis, mediante um discurso claro e preciso, ideias complexas, ligando-as a situações concretas da vida real. Trata-se de um pensamento sempre vigilante e crítico, nunca panfletário, prenhe de perspectivas construtivas, marcado por um otimismo trágico que o faz sempre atento às contradições do real, sem fechar as portas à esperança. 


\section{A hermenêutica da contemporaneidade}

Tecido numa intensa e extensa conversação com os pensadores clássicos, dos antigos aos atuais, o pensamento de Pedro Goergen sobre a educação testemunha uma densa erudição filosófica, acompanhada de atenta observação da realidade histórico-social dos tempos atuais. Daí minha convicção de que designar seu modo de filosofar como sendo uma sistemática hermenêutica da cultura contemporânea é a melhor forma de expressá-la. Ele mesmo assim o diz ao enunciar como vê a tarefa da Filosofia da Educação, por sinal reportando-se explicitamente a Gadamer (2008) e a Ítalo Calvino (2009).

A filosofia, antes de tudo, deve fazer a hermenêutica (Gadamer, 2008) dessa realidade, assumindo, ao mesmo tempo, uma postura de pesquisa, de descoberta, de reinvenção do humano e da sociedade. Na sua conexão com a educação cabe à filosofia fazer a história cultural e civil do homem e refletir crítica e propositivamente sobre os sentidos e perspectivas do humano no contexto da sociedade contemporânea. Diante das adversidades cabe-lhe a coragem de propor uma revolução cultural, um projeto de progresso, a ideia de uma nova racionalidade emancipada, livre da heterodireção dos interesses da produção e do consumo, da cultura de massa, da anulação da subjetividade, da irascibilidade destrutiva e suicida. (GOERGEN, 2011p, p. 142-143).

Para o autor, a legitimação fundadora da educação é seu compromisso com a emancipação do homem em relação a todas as formas de opressão e de dominação que o confrontam em sua existência. Consequentemente, a legitimação da Filosofia da Educação encontra-se no seu compromisso com o esclarecimento das situações em que essa dominação se cristaliza, de 
forma explícita ou de forma camuflada. "A Filosofia da Educação tem como tarefa levantar as vendas dessa cegueira da razão antropocêntrica moderna, despertando no homem a sensibilidade moral, entorpecida pelo hábito de aceitar o mundo como ele é", diz Goergen (2011p, p. 137), citando novamente Ítalo Calvino.

Isso significa evitar a rendição da individualidade e da vontade humana à objetividade; significa não aceitar passivamente o mundo como é e assumir a condução do curso da história.

No transcurso do autismo subjetivista à anulação objetivista desfaz-se a distinção entre o eu e a realidade, sendo que a última se impõe e subjuga o primeiro [...]. Da mesma forma como foi preciso criticar a subjetividade, torna-se agora necessário opor-se ao domínio da objetividade. A enxurrada da objetividade amordaça o sonho e o espírito revolucionário que não aceitam a realidade injusta e cruel e deseja mudá-la (GOERGEN, 2011p, p. 137).

É todo um programa que cabe à Filosofia da Educação desenvolver na sua condição de elucidadora do sentido das práticas que concretizam a existência dos homens nos diferentes momentos de sua história. A cada tempo uma tarefa que se impõe, sempre renovada e atenta às características que a vida social vai assumindo em suas diferentes épocas históricas.

A Filosofia da Educação precisa conscientizar-se dessa tensão histórica, da paixão ético-cultural com relação ao mundo formigueiro agitado, misterioso e perpassado por um movimento aparentemente irracional. Desvendar-lhe os movimentos e influenciar seus rumos é o sentido da educação de cada ser humano. [...] ao modo socrático, a Filosofia da Educação pode e

Filosofia e Educação [RFE] - Volume 8, Número 2 - Campinas, SP Junho-Setembro de 2016 - ISSN 1984-9605 - p. 7-26 
deve ser a voz perturbadora que desperta o homem de seu sono objetivista. Este é o sentido da emancipação a ser estimulada pela filosofia: falar de atitudes, de posturas, de ideais, de valores, das dificuldades e aspirações no contexto que ameaça capturar a absorver o homem. Refletir criticamente sobre as características da vida moderna, seus ritmos mecânicos e desumanos, seus conflitos e desesperos, cotejando-os com os verdadeiros alicerces do homem de hoje, é a contribuição da filosofia para a estrutura, ideais e performances da prática educativa. Se a educação se revela inadequada, se ela se encontra em crise, é hora de repensar sua relação com o humano no contexto de um mundo complexo de necessidades e desejos em que convivem, lado a lado, tragédia e felicidade, idealismo e pragmatismo, vida e morte, sonho e desilusão, fartura e fome. (GOERGEN, 2011p, p.138-139.)

Ampliar a consciência do homem, mudar sua postura. É esta visão de conjunto e a geração de uma nova consciência uma das maiores carências do homem contemporâneo e por isso, também, a primordial tarefa da filosofia e da Filosofia da Educação (cf. GOERGEN, 2011p, p. 139). Se à educação cabe uma tarefa intrinsecamente compromissada com a emancipação dos sujeitos humanos, à Filosofia da Educação lhe cabe desvendar as tramas de todas as modalidades de opressão e de dominação que impedem esses sujeitos de fruírem autonomia em sua existência histórica.

\section{Os núcleos temáticos aglutinadores}

O refletir filosófico de Pedro Goergen sobre a educação se articula em torno de alguns direcionamentos, coerentemente articulados em torno do tema da condição da educação em suas dimensões ética e política no contexto histórico-cultural da contemporaneidade. Pois o que abastece 
permanentemente o seu discurso analítico-reflexivo é o diagnóstico da profunda crise, de natureza ética e política, da civilização atual, sempre seguido da enunciação da necessidade e da possibilidade de superação da mesma. Por isso mesmo, sua abordagem alcança uma avaliação crítica da ética tradicional, um debate igualmente crítico relacionado às propostas da ética hedonista do presentismo, que interpreta como um relativismo ético e, ao final, sempre uma abertura às exigências que se impõem para que se crie a nova ética, imprescindível e viável para que possamos assegurar um futuro digno para a humanidade.

De um outro ângulo, mas intimamente vinculado à dimensão éticopolítico, seu olhar se volta sempre para as exigências epistemológicas com vistas à construção do conhecimento específico no campo educacional, explicitando e discutindo as pretensões da tradição filosófica ocidental, seus limites e riscos. Daí o destaque que coerentemente dá à educação especificamente mediada pelo ensino superior: ao debater a situação e as responsabilidades da Universidade, como instituição funcionária que é do conhecimento, com o investimento na sua produção, sistematização e disseminação (cf. GOERGEN, 2000; 2001 es; 2003ug; 2003ur; 2006; 2008).

Entendo que podemos então sintetizar a proposta que Goergen concebe e pratica para a Filosofia, em geral, e para a Filosofia da Educação, em particular, como aquela de uma hermenêutica sustentada por reflexão sistemática, rigorosa e crítica, sobre a dimensão sociocultural, na perspectiva longitudinal do tempo histórico, abordando os contrapontos, as rupturas e continuidades, particularmente entre a modernidade e a pósmodernidade. Esta coordenada temporal tem a ver, coerentemente com seus pressupostos, com o respeito que se deve à historicidade: vivemos hoje a busca de maior clareza sobre esse momento de profunda transformação cultural da tradição consolidada pela modernidade, decorrente das crises que

Filosofia e Educação [RFE] - Volume 8, Número 2 - Campinas, SP
Junho-Setembro de 2016 - ISSN 1984-9605 - p. 7-26


sinalizam a demanda por uma nova tradição. Mas Goergen entende que a alegada pós-modernidade não é mais que um intervalo, o intervalo pósmoderno.

Sendo a prática, a ação, o núcleo forte da dinâmica da existência, compreende-se a centralidade das preocupações éticas e políticas. Pois a grande questão é a do como agir nas mudadas condições históricas de hoje. Daí o interesse nuclear pela situação ético-política da sociedade contemporânea, que perpassa todo o pensamento de nosso homenageado. De acordo com sua leitura, impera atualmente um profundo relativismo ético, que se evidencia pela desconstrução dos valores, pela primazia dos interesses individuais e pelo exacerbado hedonismo. Mas crê igualmente que, ao lado desse universo de desilusões, é possível vislumbrar possibilidades e perspectivas éticas promissoras para além do intervalo pósmoderno. Trabalha então três perspectivas: a construção da identidade ética em meio a contradições e incertezas; a tentativa hedonista de armar um novo modelo ético, livre de princípios transcendentais e universais; novas possibilidades de fundamentação ética.

\section{As contradições do existir na modernidade}

Existimos hoje num mundo marcado pela heterogeneidade e pela contradição. Mundo ambíguo que se coloca, ao mesmo tempo, como risco e necessidade. Mas isso não caracteriza uma novidade, no ver de Pedro Goergen. A condição da realização do ser humano sempre foi complexa e dilemática (cf. GOERGEN, 2005, p. 64). A heterogeneidade da expressão dos valores esteve sempre presente na história da humanidade e decorre da heterogeneidade dos interesses das diferentes classes sociais que constituem a sociedade em cada momento histórico. O mesmo se dá com os valores 
educacionais, relacionados aos objetivos da educação. Por isso, faz parte da atividade crítica da teoria

desvendar o caráter ideológico de certas formulações e afirmar os valores democráticos. Mesmo assim, tais entendimentos conduzem apenas a consensos precários, sempre sujeitos a novas tematizações discursivas e correspondentes reformulações (GOERGEN, 2005et, $67)$,

conclui o autor, apoiando-se em Habermas (1989; 1999).

Filósofos e legisladores, diante da instabilidade dos sentimentos individuais, buscaram uma referência universal na esfera dos valores que embasassem regras inflexíveis, válidas para todos, análoga à lógica no campo do conhecimento. Pretensão da modernidade que hoje se encontra abalada. Com efeito, "a razão celebrada como ciência e tecnologia, é um instrumento tanto útil quanto perigoso" (GOERGEN, 2005et, p. 69).

Livre da submissão religiosa e guiado unicamente por sua razão, o homem seria o dono de seu destino, imaginava-se. Mal desconfiavam os iniciadores desse programa que essa razão, libertadora das cadeias do autoritarismo, haveria de converter-se ela mesma numa espécie de novo deus cujas divindades menores haveriam de conduzir os homens a uma nova forma de alienação (GOERGEN, 2001et, p. 8).

A modernidade se marcou por uma

ilimitada confiança na razão, capaz de dominar os princípios naturais em proveito dos homens e a crença numa trajetória 
humana que, pelo mesmo uso da razão, garantiria à sociedade um futuro melhor. Em outros termos, o projeto moderno, sintetiza-se pela fé na racionalidade e no progresso (GOERGEN, 2001, p. 13).

Dispensou assim qualquer ordem transcendental legitimante:

A razão torna-se a nova força do homem pela qual o homem pode intervir no mundo natural e social. Além de ser um atributo do sujeito individual, a razão é alçada à capacidade de sujeito-espécie de promover a emancipação do homem através da ciência e da tecnologia. O conhecimento seguro e útil representa uma fórmula de poder que, daí em diante, assumira fascinantes e terrificantes proporções (GOERGEN, 2001, p. 17).

A modernidade via na razão a sustentação da aposta de condições para uma vida melhor, mais justa e mais feliz. Mas as catástrofes do século XX "desautorizam a razão e ofuscaram o brilho de suas promessas". Segundo suas teses,

a racionalidade moderna, incapaz de cumprir suas promessas, está sedo substituída por uma nova lógica da sedução, da hedonização da vida, da consagração do individualismo, da espetacularização de tudo, do elogio ao presente em repulsa ao passado que não é e ao futuro que não chega. [...]

Parece que a tese do advento de uma temporalidade dominada em todos os âmbitos do humano pelo precário e pelo efêmero, bem como a primazia absoluta do aqui e agora que marcaria o político e o ético, resulta de uma leitura linear e pouco dialética da história. $[\ldots]$ 
O pós-modernismo decreta o passado como morto e extinto e anuncia a chegada do reino da autonomia e liberdade como se esse pudesse ser alcançado pela simples superação dos enquadramentos religioso, sociais, políticos e ideológicos tradicionais (GOERGEN, 2005et, p. 82-83).

Para Pedro Goergen, não se trata de se retornar ao passado, à modernidade e seus modelos,

mas de argumentar que não é legítimo perder de vista a evolução dialética e contraditória da história. Por isso, no que concerne à tarefa da educação o que mais carece é a reflexão dialética, a resistência às imposições e a inauguração de uma nova positividade contra-fática, capaz de fornecer ao ser humano novo abrigo, novos sentidos, novas utopias e transcendências, novos limites e medidas (GOERGEN, 2005et, p.84).

\section{O desafio educacional na era do efêmero}

Nesse contexto de hegemonia da busca do prazer, a tendência é transformar a educação em pura instrumentalização para o hedonismo. A educação se atrela a essa ideologia, dela se tornando mediadora. Ela se torna então

a busca de instrumentalização pessoal para competir no interior de um sistema que permanece intocado. Os objetivos da escola, o currículo, o discurso dos gestores e dos próprios professores estruturam-se em função do indivíduo, da satisfação de suas necessidades profissionais e ganhos futuros e neutralizam-se os conflitos de classe, dissipa-se o imaginário revolucionário, cresce a apatia com relação aos temas mais amplos e sociais enquanto 
aumenta a efervescência em torno do eu, de suas necessidades de consumo. (GOERGEN, 2005et, p. 79-80).

O acesso universal à educação passa a ser condição sine qua non para uma reorganização social marcada pela equidade e pela justiça social:

Se postularmos a democracia e a justiça social como requisitos básicos da organização social, não é possível imaginar que tais objetivos possam ser alcançados sem acesso universal à educação de qualidade (GOERGEN, 2011p, p. 7).

Trata-se, consequentemente, de substituir e superar o modelo de educação construído no âmbito do projeto iluminista da modernidade, mas sem se iludir com o canto da sereia da pós-modernidade:

Toda a história da modernidade está marcada por uma profunda ambiguidade entre os avanços da racionalidade científica e o renitente atraso em termos de desenvolvimento humano. Conhecimento e ignorância, fartura e fome, saúde e doença, miséria e riqueza convivem lado a lado. Independentemente de quaisquer ideais transcendentes ou de determinações ontológicas, a barbárie e os riscos que ameaçam o futuro da humanidade exigem que o modelo social hoje vigente seja rediscutido (GOERGEN, 2011p, p. 9).

De igual modo, impõe-se a superação da situação atual da educação, herdada da tradição moderna, agora sob a lógica mercadológica do capitalismo hodierno: 
O modelo de educação instrumental, fortemente privado e privatista, posto a serviço, na essência, dos interesses do capital, precisa ser repensado desde a perspectiva do direito de todos ao exercício da cidadania no contexto da esfera pública, democrática e universal (GOERGEN, 2011p, p. 9).

A mais importante tarefa da educação contemporânea é encontrar formas de favorecer o desenvolvimento de um homem novo que, fortalecido na sua subjetividade, tenha consciência de sua condição humana de ser com o outro e se sinta comprometido com a construção de um ethos da convivência humana. Trata-se de uma tarefa nada fácil porque esta consciência e compromisso devem afirmar-se em meio a um mundo adverso dominado pela promoção individual, pelas vantagens do momento e pelo consumo individual. E não é fácil, também, porque pressupõe uma profunda revisão dos pressupostos e compromissos ideológicos do atual modelo escolar (GOERGEN, 2011b, p. 12).

Daí a capacidade e a responsabilidade da educação, cuja contribuição é fundamental nesse momento de superação do individualismo egoístico e hedonista:

O que se espera da educação ético-moral é que contribua para ampliar a capacidade reflexiva dos indivíduos para que a autonomia e liberdade subjetivas ampliadas possam ser resgatadas do individualismo hedonista e ser capitalizadas em favor de um novo projeto de transformação social. [...] Narciso está assustado (GOERGEN, 2005et, p. 87).

Trata-se de engajar a tomada de consciência com a ação. Com efeito, "vincular a educação a um sentido ético significa despertar a consciência 
dos educandos e agir positivamente sobre as condições objetivas, econômicas e culturais que favorecem a persistência da barbárie" (GOERGEN, 2011f, p. 144)

Comunga com Habermas, quando esse filósofo coloca a argumentação como mediação legitimadora da moral. Não há como desconhecer a condição intersubjetiva de toda ética, ultrapassando a monologia do sujeito.

A legitimação das normas e leis não mais se fundamenta no princípio da autoridade externa, mas na argumentação intersubjetiva. Não se trata, portanto, de um giro axiológico, mas de um giro pedagógico, ou seja, muda a forma de embasamento dos valores. A autoridade e os valores já não se sustentam na autoridade, mas com base no argumento (GOERGEN, 2005et, p. $88)-$

valores que "dependem essencialmente de uma conversão íntima e que, portanto, só podem ser legitimados pela adesão alcançada através de um processo argumentativo" (GOERGEN, 2005et, p. 88).

Não se trata mais de disciplinar, de impor valores e sentidos mediante ameaças e castigos, mas de convencer os educandos, através de argumentos racionais da importância e necessidade de certos princípios orientadores como consensos reguladores da vida do homem em sociedade (GOERGEN, 2005et, p. 89).

Essa necessária formação ético-política é imprescindível nas coordenadas histórico-culturais da contemporaneidade: é posição recorrentemente enfatizada pelo nosso autor. Por mais que sejam legítimas as críticas feitas às pretensões das metanarrativas tradicionais ou modernas, 
não se pode abrir mão da busca de referências ético-políticas para nossa ação. Isso porque não se pode abrir mão da busca de uma vida digna, respeitosa e solidária numa sociedade justa e democrática (cf. GOERGEN, 2005ed, p. 989)

Goergen está ciente da complexidade da formação moral e das múltiplas implicações, tanto no âmbito das iniciativas pessoais como daquelas de cunho social. Ela supõe uma base mínima de autonomia do sujeito, o que já envolve o esclarecimento e a capacidade de decisão livre. É por isso mesmo que a educação se constitui como uma importante mediação para essa formação.

Mas por outro lado, o sujeito nunca conhece, decide e age sozinho, isolado. Ele sempre se encontra entretecido na malha social, como bem o demonstra sua imbricação numa cultura e, particularmente, seu vínculo com uma linguagem. $\mathrm{O}$ ser humano só vive, convivendo com os seus semelhantes.

A formação moral é um processo complexo que abriga diversos aspectos, desde a incorporação das convenções sociais até a formação da consciência moral autônoma. As formas de aquisição de tais requisitos incluem a reflexão e as atitudes pessoais até os sentimentos e comportamentos que são estimulados pela educação formal ou informal, como também pela simbiose ou mímese cultural. A educação moral, entendida como o conjunto de todos estes movimentos, é um processo de construção sociocultural da personalidade ou do sujeito moral.

O ser humano só é ou só pode ser um sujeito moral na medida em que é indeterminado e livre. Se fôssemos programados como os animais, não poderíamos falar de moralidade. De outra parte, a liberdade implica a capacidade de refletir sobre o processo de 
aprendizagem e a capacidade de dar a este processo a orientação que desejamos. Quando nos encontramos diante da decisão de como desejamos viver, que atitudes tomar ante os conflitos vitais, como nos relacionar com o meio e com os outros, estamos diante da condição humana que denominamos moralidade. É o jogo entre a determinação e a possibilidade de decidir a respeito da orientação que queremos dar à nossa vida. Disso já é possível extrair uma primeira elucidação do que é educação moral: a busca de um caminho pessoal para uma vida consciente, livre e responsável. Do ponto de vista do educador, pode-se dizer que sua influência educativa deve contribuir para um sujeito consciente e autônomo, capaz de decidir que atitudes tomar e que, na busca da felicidade, preservem tanto interesses individuais quanto sociais. (GOERGEN, 2005ed, p. 1005).

A essa primeira junta-se uma segunda e importante dimensão, geralmente secundarizada pelas éticas individualistas ou subjetivistas. Se concordarmos que o protagonista do processo de atitudes e decisões é, antes de tudo, o sujeito individual e autônomo, é preciso acrescentar imediatamente que esse sujeito não existe, não pensa, nem age sozinho. $\mathrm{O}$ ser humano por sua própria condição humana vive e age em situação social. Ademais, sua linguagem, sua forma de pensar, de sentir e de julgar são fruto da história de suas relações com a natureza e com os outros homens. É no contexto da convivência que se abrem para ele todas as possibilidades, mas também se impõem os limites e as normas (cf. GOERGEN, 2005ed, p.1007).

Precisamos, pois, de uma nova consciência para enfrentarmos os graves desafios que se apresentam para nós, na contemporaneidade, tanto em nossa condição de pessoas individuais como na condição de integrantes 
da sociedade humana, como um todo. Necessidade de uma nova ética e, consequentemente, de uma nova educação, o que demanda uma racionalidade revisada em que haja mais lugar para o diálogo, para a solidariedade e para a alteridade.

\section{Considerações finais}

Estamos diante de um cenário de preocupação mas também de esperança. A reflexão de Pedro Goergen situa-se nesse espaço do debate teórico entre o pensamento moderno, marcado por uma excessiva confiança na razão, e o pensamento pós-moderno, que pretende desconstruir o edifício racional. A posição do autor é de afirmar a necessidade da busca de novos caminhos sem desconsiderar a imprescindível contribuição da razão.

Goergen explora, em sua reflexão, os contrapontos entre as alegações da modernidade e aquelas da pós-modernidade, derivando dessa discussão as implicações para o campo da ética, da política e da educação. Trabalha então com a proposta cognitivista da razão comunicativa de Habermas em contraposição às teses de Lipovetsky, com sua hipótese de vivermos uma época pós-moralista. E como esse ingente debate impacta a educação.

Assumindo-se na linha da tradição inaugurada pela Teoria Crítica da Escola de Frankfurt, apoia-se particularmente na posição teórica de Habermas, reconhecendo

as aporias do projeto iluminista sem, no entanto, abrir mão do conceito moderno de razão e da possibilidade de, à sua luz, construir um projeto emancipador da humanidade, e discordando, por conseguinte, da posição dos chamados pós-modernos segundo os quais o conceito de razão com traços de universalidade e a 
possibilidade de interferir nos caminhos da humanidade são ideias do passado, hoje vazias de sentido (GOERGEN, 2001, p. 2).

E a reconstrução da ética é a tarefa fundamental do pensamento contemporâneo se quisermos garantir o futuro de cada um e de todos.

Goergen é plenamente coerente com essa promessa. E ele vê os sinais de uma nova consciência:

Parece que se tornam visíveis os primeiros sinais de uma nova percepção, uma consciência de que é urgente e também possível fazer algo para curar as feridas da profunda degradação em que a sociedade fecha o segundo milênio. A ciência e a tecnologia, os dois fogosos cavalos de batalha do iluminismo conduziram a carruagem do mundo ocidental, a par dos lugares de conforto e de bem-estar, à beira dos abismos assustadores das dicotomias individuais e sociais em que segurança e fragilidade, conhecimento e ignorância, riqueza e pobreza, saúde e doença, opulência e miséria, vida e morte coabitam lado a lado. No contexto do sistema econômico neoliberal, ocorre um distanciamento cada vez maior entre os grupos que colhem às fartas os frutos do desenvolvimento científico-tecnológico e aqueles que ficam à margem do caminho condenados à fome e à miséria. Os desígnios do deus mercado, regido por lógica própria, não podem ser contrariados com o argumento de que seus resultados são parciais, que favorecem alguns e desgraçam outros. $\mathrm{O}$ grande mote da última década foi o da globalização da economia que, desimpedida dos "entraves" do Estado e da preocupação social e deslizando pelos azeitados trilhos da tecnologia da informação, deu fim a qualquer projeto ou mesmo controle social e político (GOERGEN, 2001, p. 6). 


\section{Referências bibliográficas}

ADORNO, Theodor \& HORKHEIMER, Max. Dialética do esclarecimento. Rio: Zahar, 1985.

BAUMAN, Zygmunt. Ética pós-moderna. São Paulo: Paulus, 1997.

CALVINO, Ítalo. Assunto encerrado: discursos sobre literatura e sociedade. São Paulo: Companhia das Letras, 2009.

GADAMER, Hans-Georg. Verdade e método. Petrópolis: Vozes, 2008

GOERGEN, Pedro L. A crise da identidade da universidade moderna. In: SANTOS F', J. C. dos; PEREIRA, E. M. A.; GOERGEN, P. (orgs.). Escola e a Universidade na Pós Modernidade. Campinas: Mercado de Letras, 2000, p. 101-163. Pós-Modernidade Ética e Educaşão. Campinas: Autores Associados, 2001. $91 \mathrm{p}$

A instituição universidade e sua responsabilidade social: anotações críticas. Quaestio (UNISO), Sorocaba, p. 9-26, 2002.

. Ética e Educação: o que pode a escola? In: LOMBARDI, José Claudinei; GOERGEN, Pedro (orgs.). Ética e Educação: reflexões filosóficas e históricas. Campinas: Autores Associados, 2005, p. 59-81.

. Universidade e compromisso social. In: RISTOFF, Dilvo; GIOLLO,

Jaime e DIAS SOBRINHO, José (orgs.). Universidade e compromisso social. Brasília: Unesco, Inep e MEC, 2006, v. 4, p. 65-95.

Universidade e globalização: entre a adesão e o dissenso. In: ZAINKO, Maria Amélia Sabbag; GISI, Maria de Lourdes (orgs.). Políticas e Gestão da Educação Superior. Florianópolis: Insular, 2003, p. 129-160.

Universidade e responsabilidade social. In: LOMBARDI, José Claudinei (org.). Temas de pesquisa em educação. Campinas: Autores Associados, 2003, v. 1, p. 101-122. 
Ética e educação: o que pode a escola? In. LOMBARDI, J. Claudinei e GOERGEN, Pedro. Ética e educação: reflexões filosóficas e históricas. Campinas: Autores Associados/HISTEDBR, 2005, p. 59-95.

Educação e valores no mundo contemporâneo. Educação \& Sociedade. Campinas, v. 26, n. 92, p. 983-1011, 2005ed.

A Universidade e a dialética do esclarecimento. In: PUCCI, Bruno; ZUIN, Antonio \& LASTÓRIA, Luiz A. (orgs.). Teoria Crítica e inconformismo: novas perspectivas de pesquisa. Campinas: Autores Associados, 2010, p. $217-$ 244.

Filosofia da educação entre a integração e a emancipação. In: SEVERINO, Antonio J.; ALMEIDA, Cleide. R. S. de; LORIERI, Marcos A. (orgs.). Perspectivas da Filosofia da Educação. São Paulo: Editora Cortez, 2011f, p. 135-149.

Prefácio. In: SEVERINO, Francisca E. S. (org.). Ética e formação de professores: política de responsabilidade e autoridade em questão. São Paulo: Cortez, 2011p.

Educação para a responsabilidade social: pontos de partida para uma nova ética. In: SEVERINO, Francisca E. S. (org.). Ética e formação de professores: política de responsabilidade e autoridade em questão. São Paulo: Cortez, 2011e, p. 93-129.

HABERMAS, Jürgen. Consciência moral e agir comunicativo. Rio: Tempo Brasileiro, 1989.

Teoria da ação comunicativa. Madrid: Taurus, 1999.

LIPOVETSKY, Gilles. A era do vazio: ensaio sobre o individualismo contemporâneo. Lisboa: Anthropos, 1989.

O crepuisculo do dever: a ética indolor dos novos tempos democráticos. Lisboa: Dom Quixote, 1994. 
LIPOVETSKY, Gilles \& CHARLES, Sébastien. Os tempos hipomodernos. São Paulo: Barcarolla, 2001. 